\title{
A vision of dental education in the third millennium
}

\author{
K. A. Eaton, ${ }^{1}$ P. A. Reynolds, ${ }^{2}$ S. K. Grayden ${ }^{3}$ and N. H. F. Wilson ${ }^{4}$
}

IN BRIEF

- This final paper in a series of 16 explores how dental education may develop during the next 50 years and how elearning will play a key role.

- It considers developing technologies, some of which are already impacting on dental education.

- It brings together the aspects covered in the previous papers.

- It explains how the work of the projects will be continued in the future.

This paper is the last in a series of 16 which have explored current uses of information communications technology (ICT) in all areas of dentistry in general, and in dental education in particular. In this paper the authors explore current developments, referring back to the previous 15 papers, and speculate on how ICT should increasingly contribute to dental education in the future. After describing a vision of dental education in the next 50 years, the paper considers how ICT can help to fulfil the vision. It then takes a brief look at three aspects of the use of ICT in the world in general and speculates how dentistry can learn from other areas of human endeavour. Barriers to the use of ICT in dental education are then discussed. The final section of the paper outlines new developments in haptics, immersive environments, the semantic web, the IVIDENT project, nanotechnology and ergonometrics. The paper concludes that ICT will offer great opportunities to dental education but questions whether or not human limitations will allow it to be used to maximum effect.

\section{E-LEARNING IN DENTISTRY}

Section A: Teaching and technology

1. A description of the new technologies used in transforming dental education

2. Seeing is believing: dental education benefits from developments in videoconferencing

3. Webcasting: casting the web more widely

4. Top of the pops - CD-ROM and DVDs in dental education

Section B: Informatics: better informed by systems and services

5. Better informed: an overview of health informatics

6. Better informed in clinical practice a brief overview of dental informatics

7. Digital clinical records and practice administration in primary dental care

Section C: Impact of e-learning in

dental education

8. Remember the days in the old school yard: from lectures to online learning

9. An intricate web- designing and authoring a web-based course

10. The many faces of interaction

11. Supporting the learner and teacher online

12. Making a mark - taking assessment to technology

13. Continuing professional development and ICT: target practice

14. Assuring quality

Section D: A connected future

15. Nine years of DentEd: a global perspective

16. A vision of dental education in the third millenium

\section{INTRODUCTION}

It is often difficult to predict how things will be in the future or the rate of change. It is one thing to have new technologies and techniques available but another to have the vision and impetus to ensure that they are used and are of benefit to all concerned. Progress rarely occurs at a uniform rate and the unexpected may accelerate or retard it. Forecasting is therefore difficult, particularly with respect to the adoption of new technology. Even a few years on, forecasts in this area can be seen to be unexpectedly inaccurate. ${ }^{1}$

The previous 15 papers in this series have reviewed past and current

'Visiting Professor, UCL Eastman Dental Institute, 256 Gray's Inn Road, London, WC1X 8LD/Honorary Professor, University of Kent; ${ }^{2}$ Professor of Dental Education, Centre for Flexible Learning in Dentistry, King's College London Dental Institute, Floor 3, Strand Bridge House, 138-142 The Strand, London WC2 1 HH; ${ }^{3} \mathrm{As}-$ sistant Research Scientist, BMS/Co-ordinator, Faculty Development Dental Informatics, School of Dentistry, University of Michigan, 1011 N. University, Ann Arbor, MI 48109-1098, USA; ${ }^{4}$ Professor and Dean, King's College London Dental Institute, Central Office, Floor 18 Tower Wing, Guy's Hospital, London, SE1 9RT *Correspondence to: Professor P. A. Reynolds Email: P.A.Reynolds@kcl.ac.uk

\section{Refereed Paper}

DOI: $10.1038 /$ sj.bdj.2008.736

${ }^{\circ}$ British Dental Journal 2008; 205: 261-271 developments in e-learning in dentistry. This final paper in the series will consider how dental education may evolve in the medium and long-term and how new technologies are likely to play a part in this evolution. In particular, it will consider:

- A vision for dental education in the next 50 years

- The role of information communications technology (ICT) in fulfilling this vision

- What can be learned from the use of ICT in other areas

- Barriers to change in dental education

- Some exciting new developments: haptics, immersive environments, the semantic web, IVIDENT, nanotechnology and ergonometrics.

\section{A VISION OF DENTAL EDUCATION IN THE NEXT 50 YEARS}

Greater realisation of the benefits of good oral health and maintaining a functioning dentition throughout life, increasing expectations of dental attractiveness and trends towards demand- rather than need-driven oralhealthcareprovisionwill result in the further growth of the dental workforce, certainly internationally 
if not nationally. However, the composition of the dental workforce of the future, let alone the roles and responsibilities of the various members of the dental team, should, and hopefully will, be very different in comparison to present arrangements. The members of the dental team other than dentists - dental care professionals (DCPs) in the UK - should increasingly provide routine primary dental care, specialist services should be accessible irrespective of location, and dental practitioners should increasingly focus on those procedures which can not be delegated and should not normally be referred on to specialists. Such procedures are considered to include comprehensive oral health assessment, including risk assessment, integrated treatment planning and non-specialist forms of oral surgery, orthodontics, paediatric dentistry, special care dentistry and restorative (operative, prosthodontic, endodontic and periodontic) rehabilitation. Such arrangements will require substantial changes in the provision of dental education at all levels, with major challenges to be addressed, notably in terms of access, funding and flexibility.

Regarding a vision of the ways in which dental education will develop in the next 50 years, it is suggested that the provision will be much more diverse and diffused than at present. Dental schools will be hubs of dental education in hub and satellite structures, while all training of graduates and diplomats to a level deemed 'sufficient' by the General Dental Council will increasingly offer different educational opportunities and experiences. Some schools will place emphasis on more advanced forms of care, possibly in a specialist and research-rich environment; others may focus on communitybased approaches, possibly involving primary care networks. The remainder may offer various combinations of approaches, all of which will be necessary to produce a workforce fit for purpose. Above all else, access to education and training, value for money in the use and application of educational resources and effectiveness measured both in terms of meeting needs and return to the system will, most probably, drive change. More of the same will not suffice.
In taking matters forward, it will be important to further develop global approaches to the commonality of at least the core outcomes of dental education. To realise this goal, regulatory and other licensing bodies, as proposed in the recently published General Dental Council (GDC) Education Strategic Review Group report, ${ }^{2}$ will need to focus increasingly on outcomes rather than educational processes, which will inevitably be influenced by local circumstances and opportunities. Furthermore, there must be much more acceptance and sharing of educational resources though initiatives such as the International Virtual Dental School (IVIDENT) project, described in paper 15 in this series, ${ }^{3}$ let alone the recognition of the value of distributed learning.

Notwithstanding conflicts between, for example, the desirability of vertically integrated programmes of instruction and so-called skills escalators, it is to be hoped that ways will be found to create three-dimensional dental education frameworks within which all members of the dental team can acquire skills, knowledge and competencies in response to local needs and according to personal abilities and ambitions. Most importantly, patients must have confidence in those who provide their oral healthcare and, wherever possible, healthcare providers must be motivated to be students for life. Educational systems and regulations which frustrate these goals will fail the people they aim to serve.

\section{THE ROLE OF ICT IN FULFILLING THIS VISION}

This series of papers has previously outlined many of the ways in which the use of ICT will increasingly contribute to the fulfilment of the vision described in the previous section of this paper. Dental education, in common with most areas of human endeavour, is globalising. ${ }^{4}$ In nearly all countries there is a growing problem in that both medical and dental schools are finding increasing difficulty in recruiting and retaining academic staff. ${ }^{5}$ One answer to this problem is for all those concerned to share resources. The global conferences on dental education described in paper 15 in this series ${ }^{3}$ and initiatives such as the International Virtual Dental School (IVIDENT) and the International Federation of Dental Educators and Associations (IFDEA) Global Network on Dental Education, also described in paper $15,^{3}$ are encouraging examples of international collaboration and sharing of resources.

Distance learning (and teaching) can play a major role in this process, as distance is no object for learning, teaching or clinical practice. The increasing use of e-learning is therefore inevitable.

However, it is difficult to envisage that all learning can or should be at a distance. The answer will be the far greater use of blended learning, a combination of distance and face-to-face activities. Blended learning will enable more learning to occur in the workplace, especially where 'just in time' learning is required. Learners in practice and at home will be better connected with each other in virtual communities and to reflect on their learning. They will have greater access to materials and resources without necessarily physically going to a library or learning centre. The educational provision can be quality assured with verifiable support and feedback measures (as discussed in paper 14), ${ }^{6}$ with the benefit of a range of pedagogical approaches. Moreover, cost-effectiveness is possible for the learner by not leaving the workplace and reducing travel, while the teaching institution can gain the market lead by providing high quality educational provision that is customised and global. Education at all stages and for all members of the dental team can thus be made far more widely accessible than it has been in the past.

Technology will play an ever-increasing role. The development of virtual learning environments (VLEs), described in paper $11,{ }^{7}$ has been made possible by ever more sophisticate web tools. ${ }^{8}$ Other technologies such as haptics and nanotechnology are also likely to play an increasing role and are described later on in this paper.

However, if the vision is to be realised, human factors will be far more important than those deriving from technology. Such factors are not new. Strong leadership will be necessary to overcome reluctance to change, 
suspicion of new ideas and technology and a parochial rather than a broad outlook on education, healthcare and, indeed, life in general. Other factors such as demand from informed patients and a more enlightened attitude from administrators and politicians will also be key.

\section{WHAT CAN BE LEARNED FROM THE USE OF ICT IN OTHER AREAS?}

The question therefore arises: what can be learned from the use of ICT in other areas? The study of technology is an extremely broad field encompassing a number of areas such as human-computer interaction, social studies of science and technology and information systems, to name but a few. Each of these disciplines has university departments in their own right. It is therefore naïve to suggest that the major issues affecting ICT in dentistry, let alone all other areas of human endeavour, can be covered in any depth in a couple of pages in an academic paper. Nevertheless, a number of general issues can be highlighted which may impact on the future use of ICT within dentistry. The following paragraphs give a taste of some of these issues taken from the perspective of the study of information systems, which is a broad discipline in its own right. The field of information systems is concerned with a large range of multifaceted questions regarding the development, use and implications of ICT in organisations. ${ }^{9}$ Three themes relevant to those involved with ICT in dentistry are:

- The historical origins of ICT, which begin to explain why we experience and use ICT in the way we do

- ICT infrastructures and standards, in order to provide insight into the increasing complexity of systems used by organisations, which may lead to failure of ICT projects and other unintended consequences

- The emerging issue of information growth and the implications that this has on management of information.

\section{The historical origins of ICT}

In order to predict the future it is necessary to understand the past - in the

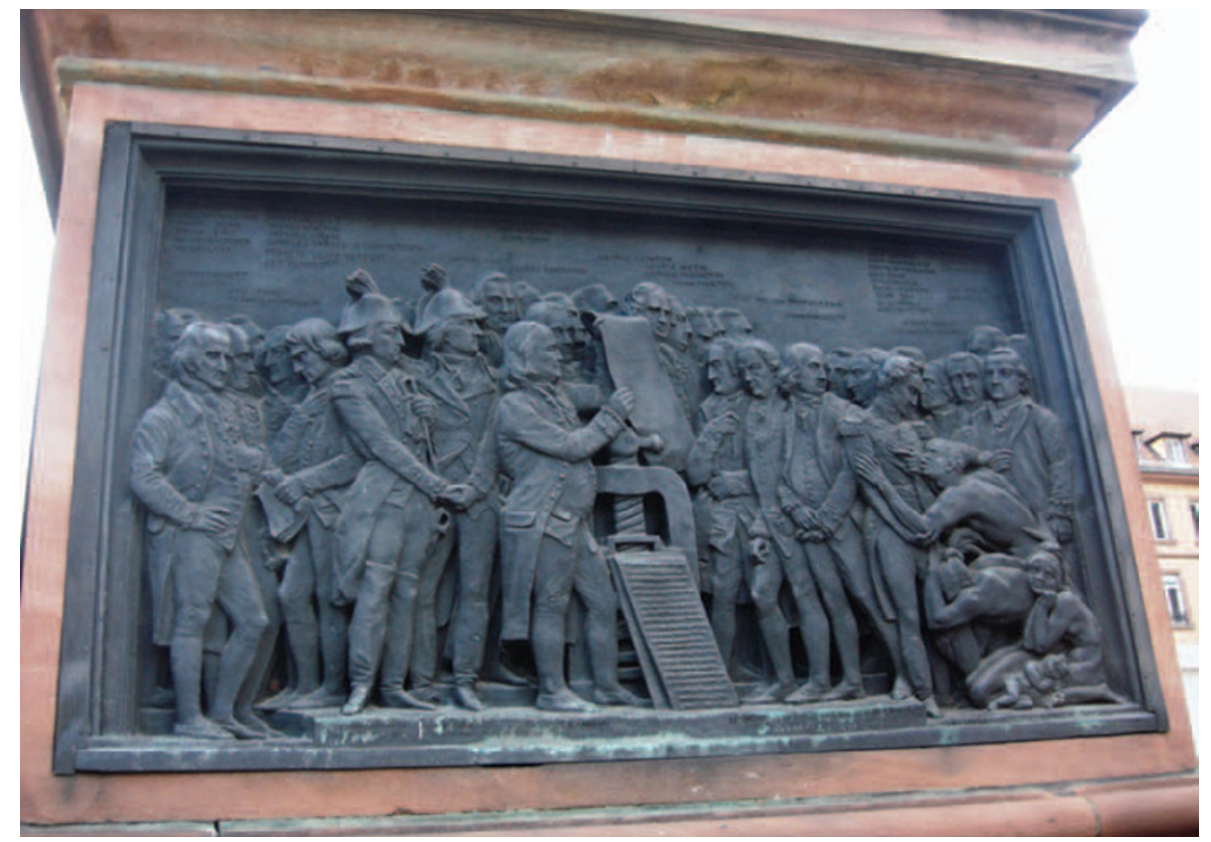

Fig. 1 Plaque commemorating the Gutenberg printing press in Strasbourg

context of this paper, the forerunners to information communications technology (ICT). In turn this gives context and informs some of the issues that face information systems today and in the future. ${ }^{10}$

ICT's origins lie within the basic modes of human communication. Throughout history, various systems and methods have been used for facilitating communication by recording and transmitting information. Communication is the means by which thoughts and meaning are transmitted through symbols between agents (human beings). It includes such means as writing, icons (such as gestures, symbols and pictures) and oral communication. Oral communication is rich in information but is often vague and lacks precision. Furthermore, oral communication is embedded in the context in which it is given. Historically, until the advent of audio recording, at best it was handed down from generation to generation and the meaning inevitably became distorted in the sands of time. Writing, on the other hand, has existed for millennia and solves the problem of speech's embeddedness as it allows the creation of collective memory by recording thought in symbolic form and its meaning can be accessed at a later date. Its meaning is divorced from the situation in which it is given, since the reader can reconstitute its context in order to understand it.
Furthermore, indexing allowed the storage and retrieval of information, methods of planning enabled past performance to be compared to current performance and future performance to be envisaged, and specialised symbols (eg mathematics, accountancy) were developed to allow specialised means of processing. In turn these non-speech forms of writing enabled the co-ordination of large organisations, from Roman Legions through to the corporations of the early twentieth century, and directly influenced the form and function of technologies preceeding ICT, such as the printing press, type writer and the early calculating machines (Fig. 1). Software and hardware that users interact with in modern ICT is an evolution of the bureaucratic methods and associated machines developed over the past century. This is not to say that they are the most suitable methods, but they are the methods most familiar to people and thus the easiest to adopt.

In addition to the ability to automatically process information, ICT introduces another key advance in the form of distance communications. Throughout history, it has been possible to send messages over long distances through signals, facilitated by such mechanisms as fire or flags and through written messages such as letters. The invention of analogue telegram, telephones and telex speeded up and improved the 
reliability of distance communications significantly. However, it is the invention of digital distance communications that has enabled the long distance networking of computing infrastructures that have transformed the productivity of bureaucracies, opening up a range of innovations from email to distance learning. This has enabled some success in delivering distance learning courses, as described in Paper $8,{ }^{11}$ and for the future delivery of elearning to be distributed widely and subsequently assessed, leading to a personalised and quality student and teacher experience. The semantic web is thus developed. ${ }^{12}$

\section{ICT infrastructures and standards}

This second theme should be viewed in a far wider context than that of a simple PC or laptop on a desk. Technology has evolved such that the PC or laptop is one component of a large infrastructure - an assemblage of many components including hardware (servers, PCs, databases etc), software and processes that facilitate complex business and organisational functions. This is the case in any Internet-based application, whether it is as simple as email or distance learning, or as complex as a networked patients' records system. ICT infrastructures facilitate bureaucracy by enabling instant access to and sharing of information, the facilitation, automation and speeding up of processes, as well as cost savings through automation of manual processes, subsequent economies of scale and increased productivity. However, at the same time ICT infrastructures introduce significant complexities into organisations and, because of their increasingly important and strategic role in bureaucracies, they are actively managed and there is a significant and frequently large cost associated with their failure. The following paragraph highlights some of the issues concerning infrastructures and the agreed standards that are used to help manage them. These issues are relevant to the infrastructures that have been introduced into general medical bureaucracy and are also likely to involve dentistry.

Problems generally occur with infrastructures as they become more widely adopted within an organisation: their user base increases as organisations become more dependent on these systems. At its simplest level, a new infrastructure is implemented at a site with no previous history of a similar system. In this case, putting the significant issues of technical implementation to one side, the key issue faced by its introduction is the issue of adoption, as while there may be individuals who stand to gain by its use, there may also be many who have much to lose. The introduction of an infrastructure is often associated with organisational change which may involve the rebalancing of roles, the loss of power or even redundancy for some individuals. Consequently, new implementations often take longer to be accepted and effectively used than is often envisaged. Replacement infrastructures face additional challenges. One issue is that of migration of users from the old system to the replacement system with minimal interruption to workers' productivity. A second issue is that of ensuring that the replacement infrastructure remains compatible with infrastructures that the previous system connected to and also that it ideally remains compatible with the system that it replaces.

The issue of backwards compatibility may limit the options available for a system to evolve and change. This leads to what is known as path dependency. ${ }^{10}$ As a consequence of path dependency, decisions regarding the replacement or evolution of ICT systems have very significant consequences. Although new solutions to solve old problems often require considerable financial outlay, there is some light at the end of the tunnel. For example, IVIDENT is designed to make all standards-based systems compatible, so rather than re-inventing the wheel, the wheel is given a new engine with plenty of oil, steerage and controls. Thus, any standard virtual learning environment (VLE) can be linked to additional, customisable, pedagogical tools and functionality such as authentication and presentation, whilst residing in an architecture that connects and records it seamlessly. This architecture is termed a 'service orientated architecture' (SOA) and the new learning environment thus created is termed a virtual learning environment 2.0 (VLE 2.0)..$^{13,14}$

In conclusion it can be speculated that as ICT becomes more powerful, there will be more pressures and reasons to use it in and across the work place. However, the advent of better standards and simple solutions will enable more accessible learning environments such as the IVIDENT model.

\section{Information growth and the implications for its management}

The third theme, one of growing interest to information systems scholars, is that of information growth. ${ }^{15}$ It is an issue that is increasingly affecting the management and use of information systems and it is thought that this is likely to become increasingly significant over the coming decades. Information is increasingly important in the post-industrial economy. ${ }^{16}$ The service economy is based around the knowledge of the professionals that work in it and information is a key resource for enhancing the output of their work as well as a source of competitive power. Information is key to modern industries, ranging from the smooth running of complex supply chains to the functioning of the global financial markets.

The past 30 years has seen an explosion in the number of devices that facilitate the creation of digital data (for example digital cameras on mobile phones), the increasing capacity for storage of digital data (for example the evolution of storage media from tape, to disc drive, to CD ROM, to DVD ROM and capacious hard disc) and lastly the range of devices and the ease with which information can be retrieved (for example mobile phone, PDA, laptop and PC, as described in paper 1). ${ }^{17}$ A technical factor explaining information growth, described in papers $5^{18}$ and $6,{ }^{19}$ is the rise of information systems and infrastructures such as NHS systems to share electronic patient records. Digital information can be tagged or indexed so that it can easily be profiled and accessed. The consequence of this is that information can easily be searched and recombined, both automatically through the generation of management information and alerts, 
as well as manually, for example the recycling, analysis and representation of news on blogs.

The final driver is the length of the useful lifespan of information. A definition of information can be considered to be data that increases knowledge - the difference that makes a difference. ${ }^{20}$

There are a number of consequences of information growth. ${ }^{14}$ Information can depreciate and needs updating. It becomes increasingly institutionalised, integrated and systematised into the fabric of society and organisations. Network technology enables these automated processes to be reconstructed and executed remotely, often far away (outsourced to the cheapest provider) from the point of execution of the original manual processes. The increasing use of virtual images is not without risks in that such virtual reality can mistakenly be reinterpreted as reality rather than as a representation of reality. Decisions based on simplified representations of reality, incorrectly understood to be reality, may lead to misinterpretation and mistakes as crucial details may be omitted. This may have been a contributory factor in the recent collapse of the financial markets, such that the underlying risks were hidden, leading to bad decisions based on data from complex financial instruments. Finally, and possibly more urgently, issues of data protection, information security and individuals' privacy can be associated with the consequences of mismanaging the ever-growing volumes of information that are generated.

In conclusion, only three aspects of the past development of ICT and the future challenges have been considered. Wider interest in and knowledge of these issues for those involved with the design, build, management and use of ICT within dentistry may promote the creation of better ICT systems and more efficient and effective working practices.

\section{BARRIERS TO CHANGE IN DENTAL EDUCATION}

As mentioned previously in this paper, perhaps the major future barriers to the use of new technologies in dental education will be due to a lack of understanding of their capabilities and a reluctance to change on the part of their potential users. An earlier paper in the current series concluded that 'unfortunately, with some notable exceptions, dental educators have hardly begun to grasp the benefits of web-based teaching and learning., ${ }^{3,21}$ This section of the paper will consider some of the barriers that will have to be overcome if the vision described in other sections is to be realised.

Over the last 30 years there has been rapid development of new technologies and educational techniques and it seems likely that this trend will continue during the 21st century. However, a number of recent publications have highlighted that dental educators have been slow to take advantage of these new developments. This paradox has been summarised in the statement that 'many innovative tools have emerged from education research but we are still struggling to determine how these tools can best be used in pursuit of our educational mission. ${ }^{22,23}$ A recent survey of electronic curriculum implementation at 66 North American dental schools found that e-curriculum implementation in these schools was following a classic innovation pattern, with a few institutions rapidly implementing while the majority made modifications slowly. ${ }^{24}$ In the United Kingdom, a review of the attitudes of undergraduates and staff to the use of electronic learning found that e-teaching was accepted more by students than by staff and that some departments were unwilling to put learning material online, even if it was password protected. ${ }^{25}$ One of the conclusions from the DentEd 1 project was that very few dental schools have introduced established ICT departments or have allocated staff to ICT teaching and research. ${ }^{26}$ Such comments and findings demonstrate typical barriers to change in dental education.

However, it is not only dental educators who have problems with new technologies. It is clear that wide acceptance and use only occurs when the systems and equipment are reliable and easy to use. No less a figure than a professor of computer design at the Massachusetts Institute of Technology has summarised the frustrations of many when equipment and programmes fail to work efficiently, in the words "the computer knows me as its enemy. ${ }^{27} \mathrm{He}$ was echoing the thoughts of Michael Dertouzos, who stated 'people are analogue, not digital; biological, not mechanical. It is time for human-centred technology, a humane technology. ${ }^{28}$

In the past ten years, change to greater use of new technologies in both dental and other areas of education has been confounded by a number of factors, including:

- Poorly designed educational material $^{29}$

- Concentration on the medium rather than the message ${ }^{30}$

- Initial funding not continued ${ }^{31}$

- A rigid curriculum ${ }^{32}$

- Poor promotion prospects for those researching the use of new technologies in education ${ }^{32}$

- An apparent lack of willingness of individuals and institutions to share ideas and materials. ${ }^{32}$

It is noticeable that the problems in the above list do not directly relate to the new technology but to human failings and attitudes that are far from new. However, there is some optimism from the 'net generation' of users who are characterised by being confident and high achievers and who, as described in paper $9,{ }^{13}$ appear to engage naturally with technology. Teachers with 20th century training inevitably have different educational perspectives to these blossoming 21st century generations.

\section{SOME EXCITING DEVELOPMENTS}

Throughout this series there has been an emphasis on education driving technology. Therefore, if new developments follow the predictions for future training needs, then dental education will reflect the changes in patient needs, treatments available and the social and political influences that will have an overarching influence on healthcare provision. As difficult as these predictions may be, there are already some emerging opportunities, such as robotics, virtual reality and nanotechnology. 


\section{Haptic technology - teaching with touch}

Haptics* is the study of human touch and interaction with the external environment via touch, and models enabling the sense of cutting enamel already exist. These include:

- Freeform (SensAble) ${ }^{34}$

- VRDTS (Virtual Reality Dental Training System) from Harvard School of Dental Medicine, USA ${ }^{35}$

- HHDTS (Handai Haptic Dental Training System) from Japan ${ }^{36}$

- Moog-FCS dental haptic device from the Netherlands. ${ }^{37}$

Simulation of a dental procedure is not new, but the cost of purchase and maintenance is well out of the range of virtually all dental practitioners and many dental schools. ${ }^{5,38}$ Furthermore, the pace of development of haptic devices has not always been matched by research into the educational effectiveness of these devices. An evaluated approach comes from the PHANTOM project (Personalised Haptics when Teaching with Online Media, http://www. tlrp.org/proj/tel/tel_cox.html), which aims to develop and evaluate haptic and synthetic online devices that will be used by a range of dental students and professionals to transform the quality of their learning. ${ }^{39}$ A multidisciplinary team drawn from cybernetics, technology innovation, education, sociology and dentistry are investigating the impact of using such devices through three strands of this Economic and Social Research Council (ESRC) and Engineering and Physical Sciences Research Council (EPSRC) funded project:

- Strand 1 - the technical strand to develop, evaluate and refine haptic devices and online simulations

- Strand 2 - the curriculum and context strand to develop and refine the dental curriculum and associated teaching strategies through a blended learning approach

*Haptics has been described as 'the sensibility of the individual to the world adjacent to his body by the use of his body', ${ }^{33}$ and encompasses any operation when a human or animal feels the environment with the body or its extremities. 'Haptic' comes from a Greek term meaning 'able to lay hold of'.

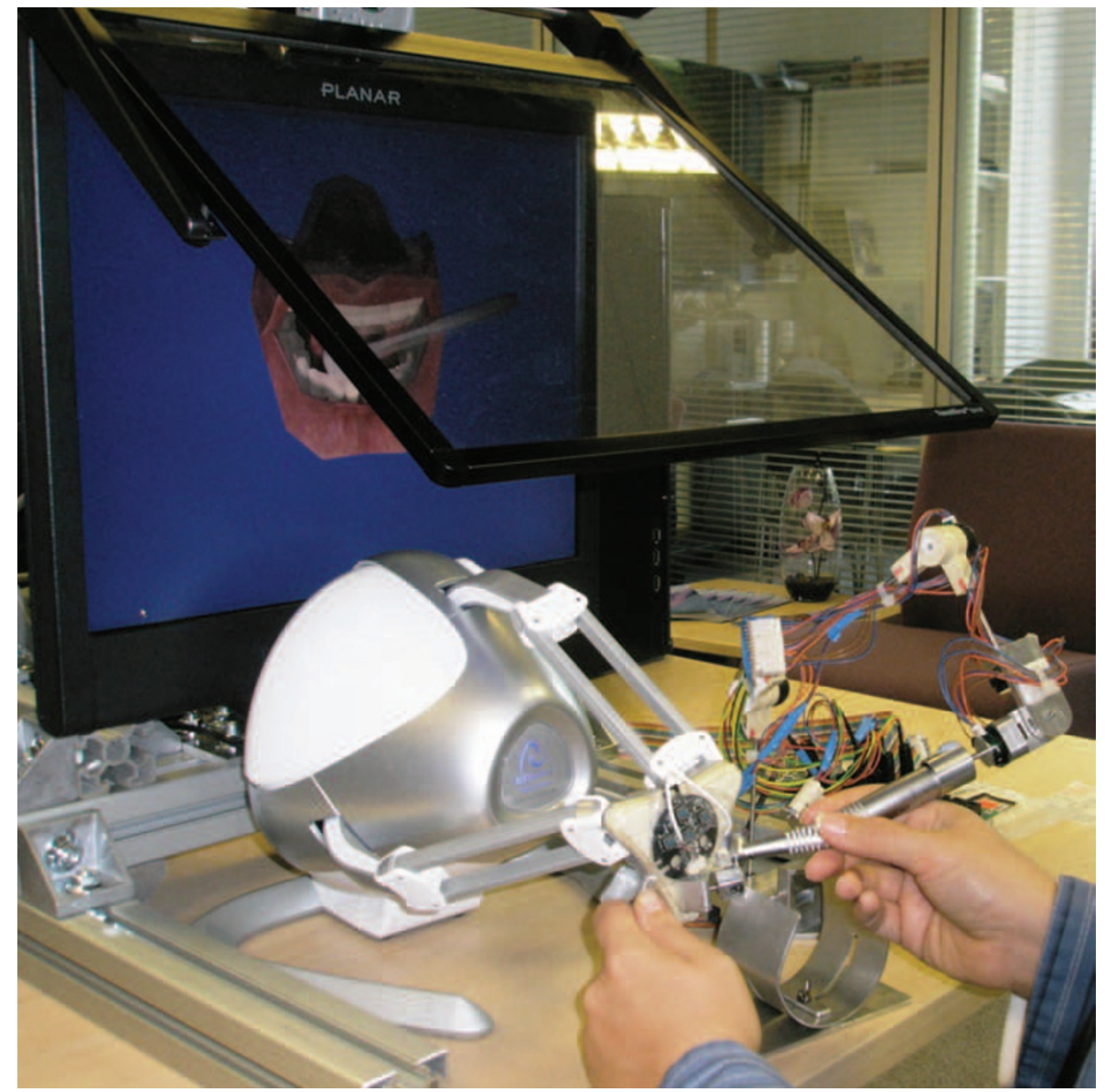

Fig. 2 One PHANTOM prototype using a Novint Falcon haptic device with 3D visualisation through a stereoscopic planar screen

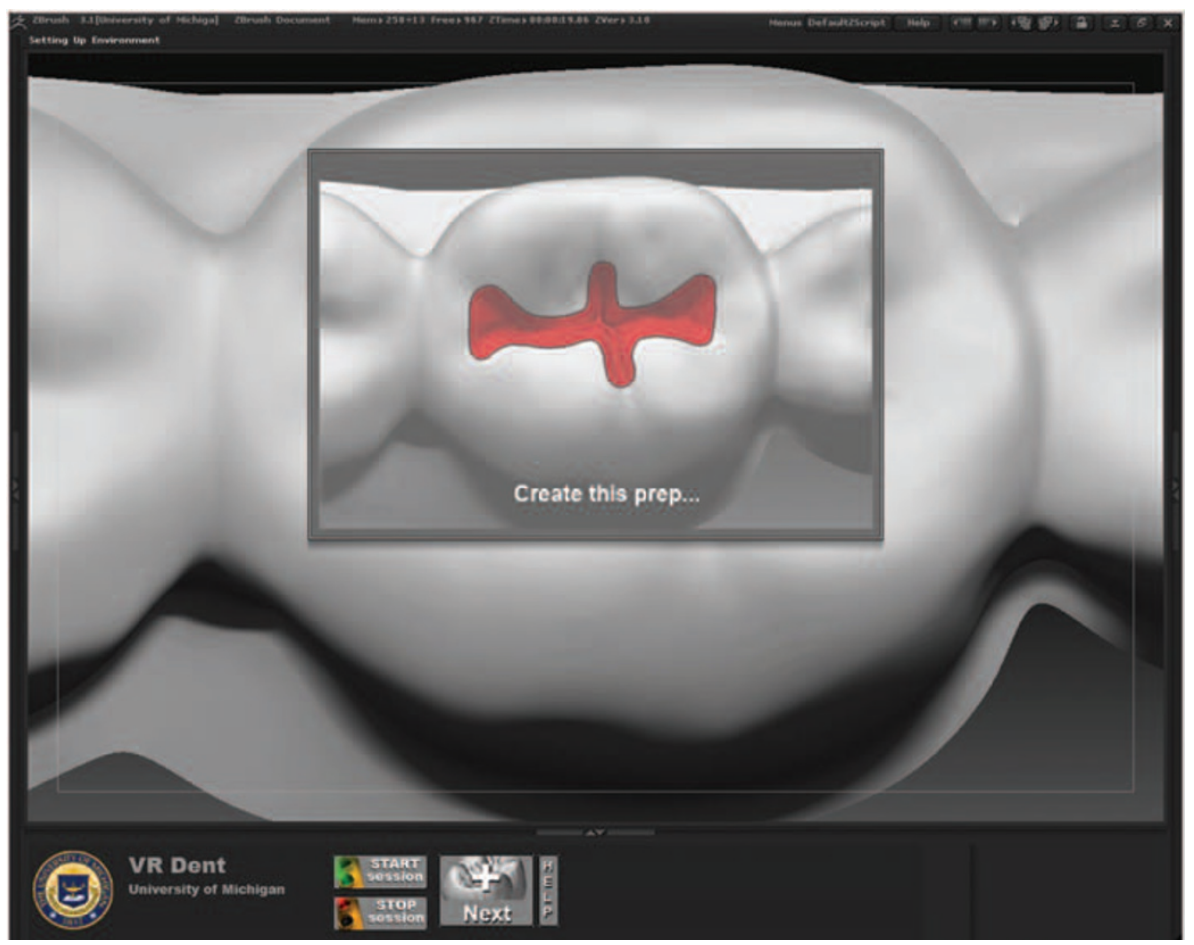

Fig. 3 Screen shot of a learning exercise used to test the LCS

- Strand 3 - the educational evaluation strand to measure the impact of the technology enhanced learning (TEL) devices on teaching and learning.
Results to date show that haptic devices can be developed to simulate traditionally taught dental skills and that effective research and evaluation 


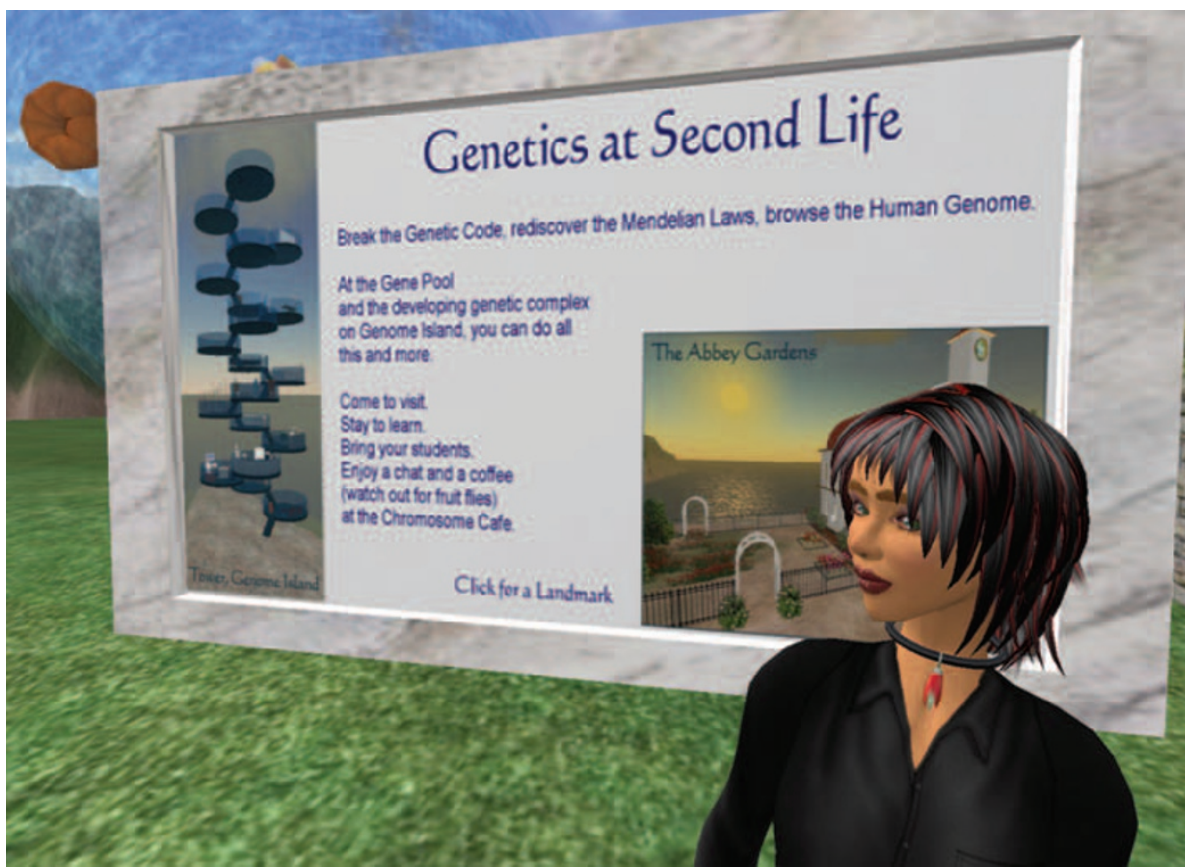

Fig. 4 An avatar interacts with content at Second Nature in Second Life

requires a range of educational theories and methods. Examples include measuring students' 3D perceptions, levels of immersion in the virtual environment, development of clinical concepts and skills, human-computer interactions, impact of the situational context, and the institutionalisation of TEL into dental education programmes. It is hoped that this approach will facilitate the development of useful technology and its incorporation into the training of dental professionals. ${ }^{40}$

The physical setup of the haptic system (Fig. 2) is being designed to include, for example, 'replaceable' dental instruments attached to the haptic device, ergonomics such as the operator's sitting position and posture, a finger rest and head-movement tracking.

The University of Michigan (USA) has developed and evaluated a series of 'low-cost simulations' (LCS) that focus on separating cognitive-versus-motor learning events in preclinical operative dentistry. ${ }^{41,42}$ Their simulation adapted sculpting software (ZBrush ${ }^{\circledR}$ by Pixo$\operatorname{logic}^{\mathrm{TM}} \quad$ - http://www.pixologic.com/ zbrush/) to create 3D interactive images of the teeth. The objective was to develop a learning tool at low cost (less than US $\$ 1,000$ ) and determine if a very simple approach (practice using a mouse that only simulates two degrees of freedom - dof $=x-y$ dimensions, limited $z$ ) could teach a concept that enhances the acquisition of a specific motor skill. First-year dental students worked on laptop computers to preview, conceptualise (cognitive) and simulate (motor) occlusal and anterior proximal cavity preparations (Fig. 3).

\section{Immersive environments}

Immersive virtual reality has been described as an artificial environment or setting that is created by a computer, in which the user feels present. ${ }^{40}$ Simulation can be taken to its next level when it is embedded in its own environment. This means that simulators and the newer haptic devices can create even greater immersion when combined with the capabilities of a 3D environment such as a CAVE (computer automated virtual environment), as previously described in papers $1^{17}$ and $9^{13}$ in this series. The potential to provide a combined visual, auditory and haptic training environment is seen in flight simulators where students can practice a range of aircraft operational skills in familiar surroundings. In similar ways, the gaming systems such as the 'Wii' mimic sporting or other activities (http://wii.com). This provides a sense of immersion or telepresence in a virtual setting that creates a learning environment which promotes transfer of skills to real world situations. ${ }^{43}$ The advantages in dental training are clear,

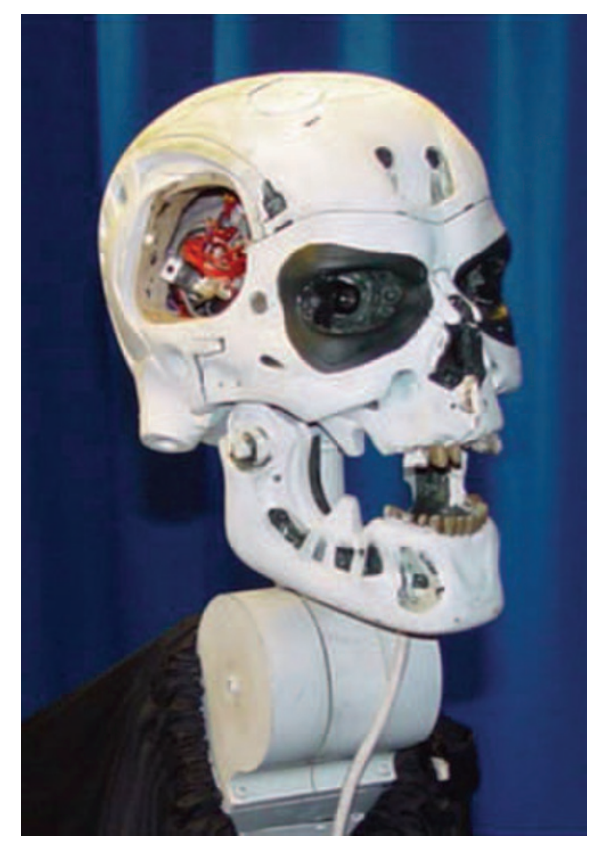

Fig. 5 The Morgui robot built at the University of Reading

but an awareness of disorientation and other psychomimetic effects requires continued monitoring. ${ }^{44}$

A multi-user virtual environment (MUVE), such as Second Life ${ }^{\circledR}$, offers user participation in a 3D environment and enhances learning (Fig. 4)..$^{39,45,46}$ Exploration of virtual space using specialised tools for learning of science has been demonstrated in Second Life employing simulations, role playing, tutorials, professional networks and data visualisations. There also are excellent opportunities for standardised patient interactions and patient-based experiences that immerse the learner into situations not possible in real life. Collaborations throughout Second Life are making possible the creation of virtual communities of scientists, educators and learners from around the world. Second Life provides a place to meet and discuss topics in virtual conferences without concern for distance or expense (http://www.youtube.com/ watch?v=EfsSGBraUhc). Teleporting within Second Life instantly transports users to new places. This increasingly plays a role in linking teachers, students and educational resources through holographic videoconferencing. 'Beam me up, Scotty' will appear a reality. ${ }^{47}$

Robots also exist that can extend the human perceptions even further. The 


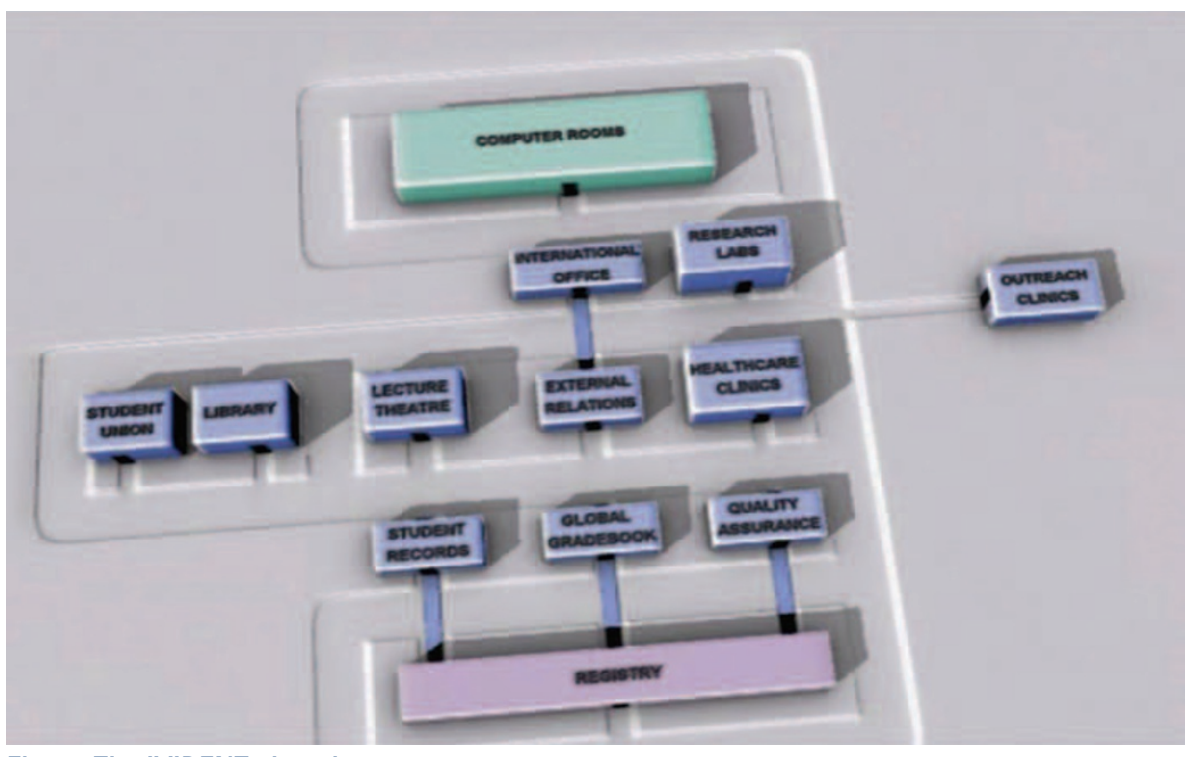

Fig. 6 The IVIDENT virtual campus

Morgui (Mandarin for 'magic ghost') was developed by the Cybernetics Department of the University of Reading and can follow users around using his five senses of vision, audio, ultrasound, radar and infrared (Fig. 5). ${ }^{48}$ Robotic dental assistants and operators are not inconceivable and future visualisation of the oral cavity and the human body using combined imaging modalities may give practitioners the 'X-ray vision' of Superman.

\section{The semantic web}

In 1989, Berners-Lee ${ }^{49}$ invented the world-wide web, which is now almost taken for granted. It has allowed unlimited links to other parts of the web, open technical standards to facilitate innovations and network layering to separate functions. Stand-alone educational packages on computers have suddenly allowed connectivity to a wide range of people, tools and resources. ${ }^{50}$ The first virtual learning environments evolved soon afterwards. The web has allowed access to untold data and global communication possibilities never thought possible 20 years ago. The development of the semantic web is evolving, in which the meanings of the links of data and services across the web are becoming more apparent. ${ }^{12}$

The semantic web is allowing even more intelligent use of educational opportunities. As described in Paper $1,{ }^{17}$ better universal systems and software connectivity such as service orientated architecture (SOA) has encouraged innovative applications to develop. It has provided the basis for the underlying structure of IVIDENT. ${ }^{3}$

\section{IVIDENT}

IVIDENT is a Higher Education Funding Council of England (HEFCE) and Department of Health in England funded project (http://www.ivident.info). Its flexible learning platform (FLP) is an SOA and provides a blueprint that enables customised and seamless integration with any other IT infrastructure, as described earlier. SOA is being used increasingly to create 'connected campuses' across the UK. Figure 6 is the IVIDENT virtual campus that has grown after scoping the needs of dental education. Each 'building' has a specific electronic role in teaching and learning. The library, for instance, is a learning content management system, and the lecture theatre and classrooms a pre-existing VLE. By connecting e-learning to clinics, in part by the use of mobile technologies and the use of 3D simulations, blended learning will be facilitated as discussed earlier and described in paper $8 .{ }^{11}$

The main benefit arising from IVIDENT should be to overcome the national problem of a shortage of highly trained academic staff available to provide teaching, particularly in oral radiology, pathology, human disease and oral medicine. IVIDENT will generate learning materials and assessment for hard pressed dental specialties and it can then be used globally. In the schools involved, it is considered that this approach should ensure optimum utilisation of teachers and resources. ${ }^{3}$

\section{Nanotechnology}

Nanotechnology refers to a field of applied science and technology whose theme is the control of matter on the atomic and molecular scale, generally 100 nanometres or smaller, and the fabrication of devices or materials that lie within that size range. ${ }^{50}$ The materials used have dimensions measured in nanometres (0.000001 millimetres). They have unusual physiochemical properties which make them useful in various areas, including medicine, electronics, optico-electronic systems and food and cosmetic products. The potential uses of this technology in all areas of human endeavour are immense and include the possibility of producing nanorobots which could be introduced into the body to repair diseased or damaged tissue. ${ }^{51}$ In the mouth, the question arises: could nanorobots be used to treat oral cancers and to rebuild damaged periodontal and pulp tissues? However, little is known of the long-term effects on human tissues and the environment and the Health Protection Agency has recently announced the development of a National Nanotechnology Research Centre to study these potential problems. ${ }^{52}$ In some ways nanotechnology seems to be the stuff of science fiction, and yet in 50 years time...

\section{Ergonometrics}

A more pressing problem for the next decade, rather than 50 years time, is that of escalating healthcare costs. It has been suggested that the application of ergonometrics can do much to address the problem. Ergonometrics has been defined as the application of various procedures to determine the time for an operator to perform a task satisfactorily, using the standard method in the usual environmental conditions..$^{53}$ One of the conclusions from a recent IBM disease management colloquium was that the use of IT was essential in addressing the problem. ${ }^{54}$ This would involve far greater use of telemedicine (and teledentistry) and much improved, reliable administrative systems for patient records. 
As explained in paper $7,{ }^{55}$ much has been done in this area in dentistry. However, uptake of new systems and equipment has been slow.

\section{CONCLUSIONS}

This paper and indeed the series of papers have considered a wide range of aspects relating to e-learning and reviewed the potential of e-learning in dental education. The authors believe that e-learning should become ubiquitous, with no distinction between made between modes of delivery. The approach will be appropriate to the educational needs of the individuals concerned and as ICT develops there will be new learning environments that are personalised, constantly evolving, liberating and immersive and which stimulate creative and innovative learning and clinical practice.

It is the task of universities and all providers and assessors of education and dental education to challenge and promote change. The technology will be there but will human limitations permit it to be used to maximum effect?

The scenario described by Bates: ${ }^{56}$ 'If a student from the thirteenth century suddenly found himself in a university lecture today, he would probably know immediately where he was,' emphasises the authors' opinion that 'More of the same will not suffice.'

The authors would like to thank Benjamin Eaton for his assistance in the preparation of this paper and many colleagues who have helped and contributed to the series.

1. Eaton K. The impact of the electronic media on primary dental care in the 21st century. Primary Dent Care 2000; 7: 31-34.

2. General Dental Council. Education Strategic Review Group. Final report to the Education Committee. London: General Dental Council, 2008. http://www.gdc-uk.org/NR/rdonlyres/B7C2479E61A4-4962-B109-26928C0E8034/79081/AbsolutefinalStrategicReviewGroupfinalreport.pdf

3. Reynolds P A, Eaton K A, Paganelli C, Shanley D. Nine years of DentEd - a global perspective on dental education. Br Dent J 2008; 205: 199-204.

4. Mason R. Globalising education: trends and applications. London: Routledge, 1998. ISBN 0415-18687-0.

5. Wilson N H F, Jones M L, Pine $C$, Saunders $W P_{\text {, }}$ Seymour R A. Meeting report - Looking forward: educating tomorrow's dental team. Eur J Dent Educ 2008; 12: 176-199.

6. Eaton K A, Reynolds PA, Mason R, Cardell R. Assuring quality. Br Dent J 2008; 205: 145-150.

7. Reynolds P A, Eaton K A, Mason R. Supporting the learner and teacher online. Br Dent J 2008; 204: 625-629.

8. Mason R D, Rennie F. Using web 2.0 for learning in the community. Internet Higher Educ 2007; 10: 96-203.
9. Agerou C. Information systems: what sort of science is it? Int J Manage Sci 2000; 28: 567-579.

10. Kallinikos J. The age of flexibility: managing organizations and technology. Lund: Academia Adacta $A B, 2001$.

11. Reynolds P A, Mason R, Eaton K A. Remember the days in the old school yard: from lectures to online learning. Br Dent J 2008; 204: 447-451.

12. Berners-Lee T, Hendler J, Lassila 0. The semantic web. SciAm 2001; 284(5): 34-44.

13. Reynolds P A, Harper J, Mason R, Cox M J, Eaton $K$ A. An intricate web - designing and authoring a web-based course. Br Dent J 2008; 204: 519-524.

14. Weller M. VLE 2.0 and future directions in learning environments. Presented at the First International LAMS Conference: Designing the Future of Learning Sydney, 2006. http://iet-staff.open.ac.uk/m.j.weller/ VLE\%202.doc (accessed 21 July 2008).

15. Kallinikos J. The consequences of information: institutional implications of technological change. Northampton, MA: Edward Elgar Publishing Ltd, 2006.

16. Bell D. The coming of the post-industrial society. New York: Basic Books, 1976.

17. Feeney L, Reynolds PA, Eaton K A, Harper $A$ description of the new technologies used in transforming dental education. Br Dent $J 2008$; 204: 19-28.

18. Reynolds P A, Harper J, Jenner A M, Dunne S. Better informed: an overview of health informatics. Br Dent J 2008; 204: 259-264.

19. Reynolds P A, Harper J, Dunne S. Better informed in clinical practice - a brief overview of dental informatics. Br Dent J 2008; 204: 313-317.

20. Bateson G. Steps to an ecology of mind. New York: Ballantine, 1972

21. Eaton K A. E-learning - new technologies but slow progress? Int J Comput Dent 2004; 7: 115-117.

22. Rosenberg H, Grad H A, Matear D W. The effectiveness of computer-aided, self-instructional programs in dental education: a systematic review of the literature. J Dent Educ 2003; 67: 524-532

23. Schleyer $T K$, Johnson $L A$. Evaluation of educational software. J Dent Educ 2003; 67: 112-113.

24. Hendricson W D, Panagakos F, Eisenberg E et al. Electronic curriculum implementation at North American dental schools. J Dent Educ 2004 68: 1041-1057.

25. Gupta B, White D A, Walmesley A D. The attitudes of undergraduate students and staff to the use of electronic learning. Br Dent J 2004; 196: 487-492.

26. Nattestad A, Mattheos N, Attström R et al. Dissemination and the net. In Shanley D B (ed) Dental education in Europe. Chapter 19. Budapest: Dental Press Kft, 2001. ISBN: 9630053055

27. Maeda J. Quoted in: Make it simple. The Economist 2004 October 30. pp 3-4.

28. Dertouzos M L. The unfinished revolution. New York: HarperCollins, 2001. ISBN: 9780694525034.

29. Johnson LA, Schleyer T. Development of standards for the design of educational software. Standards Committee for Dental Informatics. Quintessence Int 1999; 30: 755-762

30. Höhne S, Schumann R R. Computer-assisted learning in human and dental medicine. Int $J$ Comput Dent 2004; 7: 159-167.

31. Asselmeyer $\mathrm{H}$. Trends, current developments and concepts in distance learning and e-learning. Int Comput Dent 2004; 7: 145-157.

32. Nattestad A, Attstrom R, Mattheos N et al. Webbased interactive learning programmes. Eur J Dent Educ 2002; 6(Suppl 3): 127-137.

33. Gibson JJ. The senses considered as perceptual systems. Boston, MA: Hougton Mifflin, 1966.

34. SensAble Technologies. Haptic devices webpage. http://www.sensable.com/products-hapticdevices.htm (accessed 27 July 2008).

35. Novint. Medical and Dental webpage, Virtual Reality Dental Training System section. http://home. novint.com/products/medical_dental.php (accessed 27 July 2008).

36. Sohmura T, Yoshida Y, Takeshige F et al. Dental haptic simulator to train hand skill of student. J Dent Res 2008; 87(Spec Iss B CD-ROM):
Abstract 2962.

37. Moog FCS. Haptics webpage. http://www.moog com/simulationandtesting/solutions/haptics/ (accessed 27 July 2008).

38. Reynolds P A, Newton T, Cox M J et al. Methods to teach and evaluate dental clinical skills using haptics. J Dent Res 2008; 87(Spec Iss B CD-ROM): Abstract 2963.

39. Reynolds P A, Mason R, Harper J. The many faces of interaction. Br Dent J 2008; 204: 565-570.

40. Kneebone R L., Scott W, Darzi A, Horrocks M. Simulation and clinical practice: strengthening the relationship. Med Educ 2004; 38: 1095-1102.

41. Bauer P A, Fitzgerald M, Grayden S K et al. Simulated class-3 tooth preparation effect on subsequent psychomotor skill acquisition. J Dent Res 2008; 87(Spec Iss B CD-ROM): Abstract 2958.

42. Grayden S K, McLean M E, Bauer P A, Fitzgerald M, Maslowski E, Bayne S C. Low-cost simulation effectiveness for psychomotor learning in a complex model. J Dent Res 2008; 87 (Spec Iss B CD-ROM): Abstract 2959.

43. Williams S L. The Virtual Immersion Center for Simulation Research: interactive simulation technology for communication disorders. In PRESENCE 2006: Proceedings of the 9th International Workshop on Presence. Cleveland, Ohio, August 24-26 2006. http://www.temple.edu/ispr/prev_conferences/proceedings/2006/Williams.pdf (accessed 23 July 2008).

44. Smith S P, Marsh T. Evaluating design guidelines for reducing user disorientation in a desktop virtual environment. Virtual Reality 2004; 8: 55-62.

45. Grayden S, Reynolds P A, Anderson P, Bayne S, Fitzgerald M. Second Life as a virtual world for research and training. J Dent Res 2008; 87(Spec Iss B CD-ROM): Abstract 0098

46. Bayne G. ELI in conversation: Second Life and virtual worlds - an approach to active learning. Educause Connect podcast: http://connect. educause.edu/blog/gbayne/eliinconversationsecondli/46166/ (accessed July 27 2008).

47. Musion. Cisco On-Stage TelePresence holographic video conferencing. http://www.musion.co.uk/ Cisco_TelePresence.html (accessed 23 July 2008)

48. Radford T. University robot ruled too scary. The Guardian 2003 July 17. http://www.guardian. co.uk/uk/2003/jul/17/highereducation.science (accessed 23 July 2008).

49. Berners-Lee T. Testimony before the United States House of Representatives Committee on Energy and Commerce, Subcommittee on Telecommunications and the Internet. Hearing on the 'Digital future of the United States: part I - the future of the world wide web'. http://dig.csail.mit. edu/2007/03/01-ushouse-future-of-the-web.html (accessed 23 July 2008).

50. Wikipedia. Nanotechnology webpage. http:// en.wikepedia.org/wiki/Nanotechnology (accessed 23 July 2008).

51. Cavalcanti A, Shirinzadeh B, Frietas R A Jr, Kretly L $C$. Medical nanorobot architecture based on nanobioelectronics. Recent Patents on Nanotechnology 2007; 1: 1-10.

52. Health Protection Agency. A new research centre for studying nanotoxicology. Press Release, 23 July 2008. http://www.hpa.org.uk

53. Ergonometrics. McGraw-Hill dictionary of scientific and technical terms. 6th ed. New York: McGraw Hill Professional, 2002. ISBN: 007042313X.

54. Adams J, Mounib E, Pai A, Stuart N, Thomas R, Tomaszewicz P. Healthcare 2015: win-win or lose-lose? A portrait and a path to successful transformation. Executive summary. Somers, NY: IBM Corporation, 2006. http://www-03.ibm.com/ industries/healthcare/doc/content/bin/Healthcare_2015_Executive_Summary_r1.pdf (accessed 1 August 2008).

55. Wagner I-V, Ireland R S, Eaton K A. Digital clinical records and practice administration in primary dental care. Br Dent J 2008; 204: 387-395.

56. Bates T. Managing technological change. San Francisco: Jossey-Bass, 1999. ISBN: 978-0-7879-4681-4 